\title{
Gerard Peylet, Le Musée imaginaire de George Sand: l'ouverture et la médiation
}

\section{Valentina Ponzetto}

\section{(2) OpenEdition}

1 Journals

\section{Edizione digitale}

URL: https://journals.openedition.org/studifrancesi/46112

DOI: 10.4000/studifrancesi.46112

ISSN: 2421-5856

\section{Editore}

Rosenberg \& Sellier

\section{Edizione cartacea}

Data di pubblicazione: 1 octobre 2007

Paginazione: 467

ISSN: 0039-2944

\section{Notizia bibliografica digitale}

Valentina Ponzetto, «Gerard Peylet, Le Musée imaginaire de George Sand: I'ouverture et la médiation», Studi Francesi [Online], 152 (LI | II) | 2007, online dal 30 novembre 2015, consultato il 24 novembre 2021. URL: http://journals.openedition.org/studifrancesi/46112 ; DOI: https://doi.org/10.4000/ studifrancesi.46112

Questo documento è stato generato automaticamente il 24 novembre 2021.

\section{(c) 9 (i) $\Theta$}

Studi Francesi è distribuita con Licenza Creative Commons Attribuzione - Non commerciale - Non opere derivate 4.0 Internazionale. 


\title{
Gerard Peylet, Le Musée imaginaire de George Sand: l'ouverture et la médiation
}

\author{
Valentina Ponzetto
}

\section{NOTIZIA}

GERARD PEYLET, Le Musée imaginaire de George Sand: l'ouverture et la médiation, Paris, Nizet, 2005 , pp. 263.

1 Il volume comprende un insieme piuttosto disparato di saggi su diversi aspetti dell'immaginario di George Sand riuniti intorno ai concetti di apertura e mediazione. Questi costituiscono, secondo Gérard Peylet, due assi portanti e strettamente articolati della scrittura sandiana. Il tema dell'apertura infatti, sia essa spaziale o sociale, inscritta nella struttura del racconto nella psicologia dei personaggi, è sempre bilanciato da una volontà di mediazione dialettica fra gli estremi, riflesso dell'amore della romanziera per l'armonia, ma anche indice della complessità e delle tensioni opposte che animano il suo mondo.

2 Gli studi qui raccolti si articolano in cinque sezioni dedicate ad altrettanti temi: l'apertura in senso lato, lo spazio e i luoghi, la musica e la voce, l'educazione, la dialettica. L'apertura è a sua volta considerata sotto tre aspetti molto diversi. In «La frontière, lieu d'égarement et de quête dans Teverino» la dimensione del viaggio e dell'attraversamento della frontiera tra Francia e Italia mette in scena un'apertura spaziale che prende risonanze simboliche e psicologiche. In «Eschatologie et mythe du progrès dans Spiridion» l'apertura è invece temporale, visione che abbraccia il cammino della Storia e il divenire dell'Umanità. Infine «La Symphonie pastorale et le rêve aérien» apre l'immaginazione a riflessioni cosmiche e metafisiche a partire dalla musica di Beethoven.

3 La sezione dedicata ai luoghi sottolinea e analizza l'alternanza nei romanzi sandiani fra esattezza topografica e valenza simbolica dei luoghi, fra apertura verso paesaggi mediterranei, la luce e le atmosfere del Sud (ad esempio in Un Hiver à Majorque e 
Tamaris) e ritorno tanto geografico quanto affettivo al Berry e al suo mondo semplice e contadino.

4 La figura della mediazione domina invece la sezione dedicata alla musica. La musica e la voce sono infatti uno strumento privilegiato di fusione dell'interiorità con il mondo esterno («La voix et la musique dans le paysage sandien»), della natura con lo spirito, della coscienza con l'inconscio. Il musicista, incarnato in modo esemplare da Consuelo, assurge a figura quasi mitica di mediatore per eccellenza, depositario di un linguaggio totale e universale che trascende tutte le altre forme di comunicazione.

Il tema dell'educazione, tanto caro a George Sand lungo tutto l'arco della sua carriera, propone l'ideale di conciliazione fra le opposte tendenze della ragione e del sentimento e quello di piena realizzazione dell'individuo, a cui un'adeguata formazione può permettere di superare tutte le barriere sociali, culturali o psicologiche. Dei tre saggi qui dedicati all'educazione il primo è imperniato sulla figura della nonna di George Sand e sul suo ruolo esemplare di educatrice nell'Histoire de ma vie; il secondo tratta del tema scottante dell'educazione delle donne e del potere morale che secondo la romanziera dovrebbe spettare loro in quanto prime educatrici dell'umanità; il terzo, infine, analizza il modello di formazione artistica ideale proposto nel romanzo Le Château des Désertes.

6 La dialettica a cui è intitolata l'ultima sezione del saggio è soprattutto quella fra mondo arcaico e modernità. L'immaginazione creatrice di George Sand appare infatti contesa fra l'utopia arcaizzante dei romans rustiques, quasi una riproposta del mito dell'età dell'oro, e l'utopia progressista dei romanzi cosiddetti "sociali". A dire del critico, attraverso evoluzioni successive del pensiero la romanziera sembra tendere vieppiù alla conciliazione fra queste e altre opposte tendenze grazie alla duttilità della sua scrittura, alla sua sensibilità, alla sua disponibilità nei confronti del mondo e degli altri. L'immaginazione, soprattutto, assicurerebbe un'ideale unità del multiforme corpus sandiano e anche, almeno nell'abile retorica dell'introduzione, quella del presente volume di Gérard Peylet. 